\title{
ANALISIS FAKTOR-FAKTOR YANG MENINGKATKAN KEPERCAYAAN PELANGGAN MELAKUKAN ONLINE SHOPPING DAN DAMPAKNYA TERHADAP MINAT BELI ULANG Studi pada Pelanggan Online Shopping di Kota Tangerang
}

TARTO DAN YANTHI MEITRY GUNAWAN

Fakultas Ekonomi dan Bisnis, Universitas Muhammadiyah Tangerang

The purpose of this study was to analyze how much influence the knowledge of internet technology, company quality and website quality on customer trust, the effect of product quality and customer trust on risk perceptions and their impact on repurchase interests in online shopping customers in Tangerang City. The research sample is 98 online shopping customers in Tangerang City. The sampling technique used convenience sampling. Data collection distributed questionnaires via email. The method used in this study is the verification method to determine the influence of knowledge of company quality internet technology and website quality on customer trust, the influence of product quality and customer trust on perceived risk and its impact on repurchasing interests in online shopping customers in Tangerang City. The test statistics used are designing structural models, designing measurement models, building flowcharts, testing the appropriate models. Suitability test of structural models and hypotheses using SmartPLS 3.0 software.

Keywords: Knowledge of Internet Technology, Company Quality, Product Quality, Website Quality, Customer Trust, Perceived Risk of Repurchasing Interest 


\section{PENDAHULUAN}

Dalam bidang perdagangan, internet mulai banyak dimanfaatkan sebagai media aktivitas bisnis terutama karena kontribusinya terhadap efisiensi online shopping sekarang ini muncul sebagai aplikasi populer dalam e-commerce, digunakan oleh beberapa jenis bisnis dengan tujuan yang berbeda (Cheung, 1998), dan sebagai alat pertukaran informasi (Hong, 1999). Dengan menggunakan aplikasi online shopping pembelian dapat dilakukan tanpa terbatas oleh tempat.

Bagi pelanggan online, melakukan transaksi dengan vendor secara online akan mempertimbangkan ketidakpastian dan resiko jika dibandingkan dengan transaksi jual beli secara tradisional. Penelitian Doney, Cannon dan Mullen (2003); Bhatnagar; Misra dan Rao (2000)) menunjukan bahwa kepercayaan adalah faktor yang sangat signifikan dalam menjelaskan proses online shopping. Faktor-faktor yang dapat meningkatkan kepercayaan pembeli terhadap online shopping antara lain pembeli memiliki pengetahuan akan teknologi, memiliki web site yang mutunya baik, memiliki mutu perusahaan yang baik.

Young dan Dan (2005) menjelaskan bahwa pengetahuan teknologi internet sangat berpengaruh terhadap hasil yang diharapkan pengguna dalam bertransaksi melalui website. Sedangkan dalam penelitian Bramall, Schoefer dan McKechnie (2004), Mutu Perusahaan sering di gunakan oleh pelanggan sebagai indikasi sejauh mana perusahaan atau web vendor dapat dipercaya oleh para pelanggan dan seberapa jauh perhatian perusahaan terhadap para pelanggan.

Tampilan website yang profesional memberikan pelanggan rasa nyaman, maka dengan begitu pelanggan dapat lebih percaya dan nyaman dalam melakukan pembelian. (Chen and Dhillon, 2003). Sesuai dengan latar belakang yang dikemukakan, maka rumusan masalah yang dibangun sebagai berikut:

Apakah pengetahuan teknologi internet berpengaruh terhadap kepercayaan pelanggan?, Apakah mutu perusahaan berpengaruh terhadap kepercayaan pelanggan?, Apakah mutu website berpengaruh terhadap kepercayaan pelanggan?, Apakah mutu produk berpengaruh terhadap persepsi risiko? ,Apakah kepercayaan pelanggan berpengaruh terhadap persepsi risiko?, Apakah persepsi risiko berpengaruh terhadap minat beli ulang?

\section{KAJIAN LITELATUR}

\section{Pengetahuan Teknologi Internet}

Pengetahuan konsumen dapat menentukan tingkat kepercayaan pada webstore dan niat mereka untuk melakukan pembelian. Jika konsumen lebih memahami internet mereka akan lebih percaya diri terhadap webstore. Mengetahui dan memahami lebih mendalam tentang internet hingga tentang kemungkinan ancaman dan resiko yang ditimbulkan akan membuat konsumen dapat memahami metode belanja online secara baik untuk mencengah penipuan dalam menciptakan kepuasaan dan kepercayaan. (Wang, Chen dan Jiang, 2009)

\section{Mutu Perusahaan}

Mutu Perusahaan dapat diartikan sebagai kesan total yang diberikan pelanggan terhadap perusahaan online itu sendiri (Watchfire Whitepaper series, 2000) yang didapatkan dari hasil pengamatannya terhadap alat-alat marketing yang diberikan oleh perusahaan.

\section{Mutu Website}

Mutu website perusahaan yang bergerak di bidang perdagangan online merupakan faktor yang dapat mempengaruhi keputusan pelanggan. O'Keefe dan McEachern (1998) menyatakan website perusahaan yang bagus tidak hanya memberikan informasi mengenai produk yang dibutuhkan oleh pelanggan, tapi juga membantu pelanggan dengan langkah-langkah yang mudah dalam proses pembeliannya dan infrastruktur perusahaan $e$ commerce secara fisik juga sangat penting.

\section{Mutu Produk}

Mutu merupakan istilah yang mempunyai makna berbeda bagi setiap orang. Disukai atau tidak, konsumen merupakan pihak yang paling berkepentingan dalam menilai mutu yang dikonsumsinya. Tiap definisi menekankan pada aspek mutu yang berbeda meliputi kecocokan peng- 
gunaan, tingkat dimana suatu produk dapat memenuhi keinginan konsumen, dan tingkat dimana suatu produk sesuai dengan spesifikasi desain dan persyaratan teknisnya (Salim, 1995).

\section{Kepercayaan Pelanggan}

Menurut Mowen dan Minor (2002) mendeskripsikan bahwa kepercayaan adalah semua pengetahuan yang dimiliki oleh konsumen dan semua kesimpulan yang dibuat oleh konsumen entang objek, atribut, dan manfaatnya. Dalam penelitian yang dilakukan oleh Dabholkar dan Sheng (2015) menyatakan bahwa kepercayaan adalah bagian yang penting dalam konsumen berbelanja secara online.

\section{Persepsi Resiko}

Resiko memiliki dampak terhadap sikap dan tingkah laku seseorang dalam melakukan transaksi dengan pihak lain. Menurut Suryani (2008) risiko yang dipersepsikan (perceived risk) dapat didefinisikan sebagai ketidakpastian yang dihadapi konsumen ketika mereka tidak mampu melihat kemungkinan yang akan terjadi dari keputusan pembelian yang dilakukan.

\section{Minat Beli Ulang}

Menurut Suyono, Sukmawati dan Pramono (2012), minat beli merupakan bagian dari komponen perilaku dalam sikap mengkonsumsi.

\section{Pengembangan Hipotesis}

1. Hubungan Pengetahuan Teknologi Internet dengan Kepercayaan Pelanggan

H1 : Semakin tinggi pengetahuan teknologi internet, maka semakin tinggi kepercayaan pelanggan.

2. Hubungan Mutu Perusahaan dengan Kepercayaan Pelanggan

$\mathrm{H} 2$ : Semakin tinggi mutu perusahaan, maka semakin tinggi kepercayaan pelanggan.

3. Hubungan Mutu Website dengan Kepercayaan Pelanggan

H3 : Semakin tinggi mutu website, maka semakin tinggi kepercayaan pelanggan.

4. Hubungan Mutu Produk dengan Persepsi Resiko

H4 : Semakin tinggi mutu produk, maka se- makin rendah persepsi resikonya.

5. Hubungan Kepercayaan Pelanggan dengan Persepsi Resiko

H5 : Semakin tinggi kepercayaan pelanggan, maka semakin rendah persepsi resikonya.

6. Hubungan Persepsi Resiko dengan Minat Beli Ulang

H6 : Semakin rendah persepsi resiko, maka semakin tinggi minat beli ulang

\section{METODE PENELITIAN}

\section{Pendekatan dan Jenis Penelitian}

Pendekatan yang digunakan dalam penelitian ini adalah penelitian kuantitatif, pengumpulan data menggunakan instrumen penelitian, analisis data bersifat kuantitatif/statistik, dengan tujuan untuk menguji hipotesis yang telah ditetapkan (Sugiyono, 2014). Adapun Jenis penelitian yang digunakan adalah penelitian asosiatif. Penelitian

\section{Jenis dan Sumber Data}

Jenis data yang digunakan dalam penelitian ini adalah data primer. Untuk memperoleh data tersebut, peneliti menyebarkan kuesioner kepada pelanggan online shopping di Kota Tangerang melaui kuesioner.

Pernyataan-pernyataan dalam kuesioner dibuat dengan menggunakan skala 1-10 untuk mendapatkan data yang bersifat interval dan diberi skor atau nilai. Penggunaan skala 1-10 (skala genap) untuk menghindari jawaban responden yang cenderung memilih jawaban di tengah, sehingga akan menghasilkan respon yang mengumpul di tengah (grey area). Berikut kategori pengukuran; Sangat tidak setuju/Sangat setuju/setuju/buruk/baik.

\section{Penentuan Populasi dan Sampel}

Populasi dalam penelitian ini adalah pelanggan di situs belanja online di Kota Tangerang.

Teknik pengambilan sampel yang digunakan dalam penelitian ini adalah melalui pendekatan non probability sampling yaitu purposive sampling. Berdasarkan purposive sampling, peneliti memilih sampel purposif secara subjektif dan dalam pemilihan sampel digunakan pertimbangan tertentu yang disesuaikan dengan tujuan atau masalah penelitian yang dikembangkan (Ferdinand 2006). 
Syarat sampel pada penelitian ini adalah sampel berdomisili atau warga Kota Tangerang. Kriteria sampel pada penelitian ini adalah pelanggan yang pernah berbelanja sekurang-kurangnya dua kali di situs belanja online. Diperoleh sampel sebanyak 98 responden.

\section{Operasionalisasi Variabel}

Variabel-variabel yang akan diukur dalam penelitian ini yaitu:

1. Variabel bebas atau independen

Variabel independen pada penelitian ini adalah pengetahuan teknologi interner, mutu perusahaan, mutu website dan mutu produk.

2. Variabel terikat atau dependen

Variabel dependen dalam hal ini adalah kepercayaaan pelanggan, persepsi risiko dan minat beli ulang.

Variabel dan indikator yang digunakan dalam penelitian ini dijelaskan dalam Tabel 1 berikut ini:

\section{Metode Analisis}

Structural Equation Modeling (SEM) Partial Least Square (PLS) digunakan untuk mengukur hubungan setiap indikator dengan konstruknya. Selain itu, dalam PLS dapat dilakukan uji bootstrapping terhadap struktural model yang bersifat outer model dan inner model.

Langkah-langkah analisis dengan metode Partial Least Square (PLS) sebagai berikut:

1. Merancang Model Pengukuran (Outer Model)

Perancangan model ini digunakan untuk mengetahui validitas dan reliabilitas yang menghubungkan indikator dengan variabel latennya. Indikator dalam penelitian ini adalah formatik karena indikator variabel laten mempengaruhi indikatornya.

2. Merancang Model Struktural (Inner Model)

Perancangan model struktural hubungan antar variabel laten didasarkan pada rumusan masalah atau hipotesis penelitian.

\section{Konstruksi Diagram Jalur Penelitian}

1. Konversi Diagram Jalur ke Sistem Persamaan a. Inner Model

Inner Model menentukan spesifikasi hubungan antara konstruk laten satu dengan kontrak laten lainnya.

Tabel 1

Variabel dan Indikator Penelitian

\begin{tabular}{ll}
\hline \multicolumn{1}{c}{ Variabel } & \multicolumn{1}{c}{ Indikator } \\
\hline \multirow{2}{*}{ Pengetahuan Teknologi Internet $\left(\xi_{1}\right)$} & Penguasaan Teknologi Internet $\left(\mathrm{X}_{1}\right)$ \\
& Pengalaman menggunakan Internet $\left(\mathrm{X}_{2}\right)$ \\
& Pengalaman online shopping $\left(\mathrm{X}_{3}\right)$ \\
\hline \multirow{3}{*}{ Mutu Perusahaan $\left(\xi_{2}\right)$} & Reputasi $\left(\mathrm{X}_{4}\right)$ \\
& Keberadaan Mutu Fisik $\left(\mathrm{X}_{5}\right)$ \\
& Popularitas Produk $\left(\mathrm{X}_{6}\right)$ \\
\hline \multirow{3}{*}{ Mutu Website $\left(\xi_{3}\right)$} & Security $\left(\mathrm{X}_{7}\right)$ \\
& Professional Design $\left(\mathrm{X}_{8}\right)$ \\
& Ease of use $\left(\mathrm{X}_{9}\right)$ \\
\hline \multirow{3}{*}{ Mutu Produk $\left(\xi_{4}\right)$} & Integrity $\left(\mathrm{X}_{10}\right)$ \\
& Competence $\left(\mathrm{X}_{11}\right)$ \\
& Credibility $\left(\mathrm{X}_{12}\right)$ \\
\hline \multirow{3}{*}{ Kepercayaan Pelanggan $\left(\mathrm{\eta}_{1}\right)$} & Integrity $\left(\mathrm{Y}_{1}\right)$ \\
& Competence $\left(\mathrm{Y}_{2}\right)$ \\
& Credibility $\left(\mathrm{Y}_{3}\right)$ \\
\hline \multirow{3}{*}{ Persepsi Risiko $\left(\mathrm{n}_{2}\right)$} & Resiko Finansial $\left(\mathrm{Y}_{4}\right)$ \\
& Resiko Produk $\left(\mathrm{Y}_{5}\right)$ \\
& Resiko Psikologi $\left(\mathrm{Y}_{6}\right)$ \\
\hline & Minat Beli dengan Jumlah yang sama $\left(\mathrm{Y}_{7}\right)$ \\
& Minat beli dengan qualitas produk yang sama $\left(\mathrm{Y}_{8}\right)$ \\
Minat Beli Ulang $\left(\mathrm{n}_{3}\right)$ & Minat Beli dengan menambah jumlah $\left(\mathrm{Y}_{9}\right)$ \\
&
\end{tabular}

Sumber: Hsu dan Chiu (2004), Corporate Reputation Review, Vol.7, No.2, 2004, pp.125-146, Yoo dan Donthu (2001), Hansen dan Mowen (2005), Kracher dan Wiedenbeck Kracker (2003) 


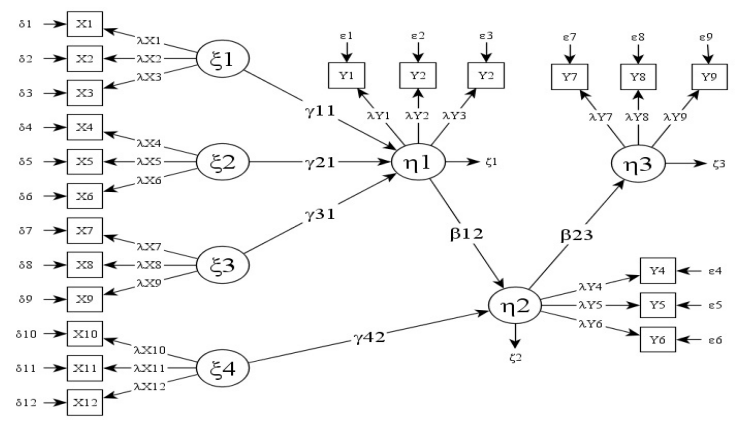

Gambar 1. Konstruksi Diagram Jalur Penelitian

Persamaan Inner Model:

$\boldsymbol{\eta}_{1}=\gamma_{11} \xi_{1}+\gamma_{21} \xi_{2}+\gamma_{31} \xi_{3}+\zeta_{1} \boldsymbol{\eta}_{2}=\gamma_{42} \xi_{4}+\boldsymbol{\beta}_{12} \boldsymbol{\eta}_{1}+\zeta_{2}$ $\eta_{3}=\beta_{23} \eta_{2}+\zeta_{3}$

Keterangan:

$\xi_{1}=$ Konstruk laten eksogen Pengetahuan

Teknologi Internet

$\xi_{2}=$ Konstruk laten eksogen Mutu Perusahaan

$\xi_{3}=$ Konstruk laten eksogen Mutu Website

$\xi_{4}=$ Konstruk laten eksogen Mutu Produk

$\eta_{1}=$ Konstruk laten eksogen Kepercayaan Pelanggan

$\eta_{2}=$ Konstruk laten endogen Persepsi Resiko

$\eta_{3}=$ Konstruk laten endogen Minat Beli Ulang

$\gamma_{11}=$ Koefisien Pengetahuan Teknologi Internet terhadap Kepercayaan Pelanggan

$\gamma_{21}=$ Koefisien Mutu Perusahaan terhadap Kepercayaan Pelanggan

$\gamma_{31}=$ Koefisien Mutu Website terhadap Kepercayaan Pelanggan

$\gamma_{41}=$ Koefisien Mutu Produk terhadap Persepsi Resiko

$\beta_{12}=$ Koefisien Kepercayaan Pelanggan terhadap Persepsi Resiko

$\beta_{23}=$ Koefisien Persepsi Resiko terhadap Minat Beli Ulang

$\zeta_{1}=$ Error Kepercayaan Pelanggan

$\zeta_{2}=$ Error Persepsi Resiko

$\zeta 3=$ Error Minat Beli Ulang

b. Outer Model

Outer Model menentukan spesifikasi hubungan antara konstruk laten dan indikatornya.

Persamaan Outer Model:

$\mathrm{X}_{1}=\lambda \mathrm{x}_{1} \xi_{1}+\delta_{1}$

$\mathrm{X}_{2}=\lambda \mathrm{x}_{2} \xi_{1}+\delta_{2}$

$\mathrm{X}_{3}=\lambda \mathrm{x}_{3} \xi_{1}+\delta_{3}$

$\mathrm{X}_{4}=\lambda \mathrm{x}_{4} \xi_{2}+\delta_{4}$

$\mathrm{X}_{5}=\lambda \mathrm{x}_{5} \xi_{2}+\delta_{5}$

$\mathrm{X}_{6}=\lambda \mathrm{x}_{6} \xi_{2}+\delta_{6}$

$\mathrm{X}_{7}=\lambda \mathrm{x}_{7} \xi_{3}+\delta_{7}$

$\mathrm{X}_{8}=\lambda \mathrm{x}_{8} \xi_{3}+\delta_{8}$

$\mathrm{X}_{9}=\lambda \mathrm{x}_{9} \xi_{3}+\delta_{9}$

$\mathrm{X}_{10}=\lambda \mathrm{x}_{10} \xi_{4}+\delta_{10}$

$\mathrm{X}_{11}=\lambda \mathrm{x}_{11} \xi_{4}+\delta_{11}$

$\mathrm{X}_{12}=\lambda \mathrm{x}_{12} \xi_{4}+\delta_{12}$

Keterangan:

$\lambda x_{1}-\lambda x_{3}=$ Koefisien indikator Pengetahuan Teknologi Internet

$\lambda \mathrm{x}_{4}-\lambda \mathrm{x}_{6}=$ Koefisien indikator Mutu Perusahaan

$\lambda \mathrm{x}_{7}-\lambda \mathrm{x}_{9}=$ Koefisien indikator Mutu Website

$\lambda \mathrm{x}_{10}-\lambda \mathrm{x}_{12}=$ Koefisien indikator Mutu Produk

$\lambda \mathrm{y}_{1-} \lambda \mathrm{y}_{3} \quad=$ Koefisien indikator Kepercayaan Pelanggan

$\lambda \mathrm{y}_{4-} \lambda \mathrm{y}_{6}=$ Koefisien indikator Persepsi Resiko

$\lambda \mathrm{y}_{7-} \lambda \mathrm{y}_{9} \quad=$ Koefisien indikator Minat Beli Ulang

$\delta_{1}-\delta_{3}=$ Error indikator Pengetahuan

Teknologi Internet

$\delta_{4}-\delta_{6}=$ Error indikator Mutu Perusahaan

$\delta_{7}-\delta_{9}=$ Error indikator Mutu Website

$\delta_{10}-\delta_{12}=$ Error indikator Mutu Produk

$\varepsilon_{1}-\varepsilon_{3}=$ Error indikator Kepercayaan Pelanggan

$\varepsilon_{4}-\varepsilon_{6}=$ Error indikator Persepsi Resiko

$\varepsilon_{7}-\varepsilon_{9}=$ Error indikator Minat Beli Ulang 
Evaluasi Goodness of Fit

Nilai GoF index ini diperoleh dari averages communalities index (AVE) dikalikan dengan $R^{2}$ model. $G o F=\sqrt{\operatorname{Com} \times R^{2}}$

Nilai $G o F$ ini terbentang antara $0-1$ dengan interpretasi nilai adalah 0,1 ( $G o F$ kecil), 0,25 ( GoF moderat), dan 0,38 (GoF besar).

\section{Uji Hipotesis (Resampling Bootstraping)}

Berdasarkan tujuan-tujuan penelitian, maka rancangan uji hipotesis yang dapat dibuat merupakan rancangan uji hipotesis dalam penelitian ini disajikan berdasarkan tujuan penelitian. Tingkat kepercayaan yang digunakan adalah 95\%, sehingga tingkat presisi atau batas ketidakakuratan sebesar $(\alpha)=5 \%=0,05$. Dan menghasilkan nilai t-tabel sebesar 1,96.

Sehingga jika nilai t-hitung lebih kecil dari nilai t-tabel [t-hitung $<1.96$ ], maka $\mathrm{H}_{0}$ diterima dan $\mathrm{H}_{\mathrm{a}}$ ditolak dan Jika nilai t-hitung lebih besar dari nilai t-tabel [t-hitung $>1.96$ ], maka $\mathrm{H}_{0}$ ditolak dan $\mathrm{H}_{\mathrm{a}}$ diterima.

\section{HASIL PENELITIAN}

\section{Evaluasi Model Pengukuran}

(Uji Validitas dan Reliabilitas )

Evaluasi ini meliputi dua tahap, yaitu evaluasi terhadap convergent validity dan discriminant validity.

\section{Evaluasi Convergent Validity}

Bila nilai loading factor suatu indikator $>0,70$ dan nilai t-hitung $>1,96$; maka indikator tersebut dinyatakan valid. Sedangkan bila nilai loading factor $\leq 0,70$ dan nilai t-hitung $\leq 1,96$; maka indikator tersebut dikeluarkan dari model.

Berikut adalah evaluasi model pengukuran terhadap validitas indikator :

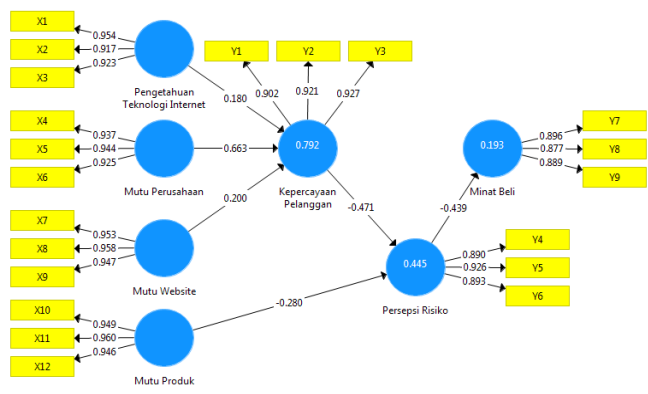

Gambar 2. PLS Algorithm Output
Semua indikator memiliki nilai loading factor $>$ 0,70; maka semua indikator dinyatakan valid.

Evaluasi selanjutnya dari convergent validity adalah reliabilitas konstruk dengan melihat nilai composite reliability dan nilai cronbach's alpha. Bila nilai composite reliability $>0,70$ dan nilai cronbach's alpha $>0,50$; maka konstruk dinyatakan reliabel.

Berdasarkan Tabel 2, semua konstruk memiliki nilai composite reliability $>0,70$ dan nilai cronbach's alpha $>0,50$; maka dapat dinyatakan semua konstruk reliabel.

Evaluasi terakhir dari convergent validity adalah melihat nilai average variance extracted (AVE). Berdasarkan Tabel 3, semua nilai average variance extracted (AVE) konstruk lebih besar dari 0,50; maka dapat disimpulkan semua konstruk memiliki convergent validity yang baik.

Evaluasi discriminant validity dilakukan dengan melihat nilai cross loadings. Kriteria dalam cross loadings adalah bahwa setiap indikator yang mengukur konstruknya haruslah berkorelasi lebih tinggi dengan konstruknya dibandingkan dengan konstruk lainnya.

Berdasarkan Tabel 4, ada dua indikator yang tidak memiliki discriminant validity yang baik yaitu indikator X8 dan X10, karena berkorelasi lebih rendah dengan konstruknya masing-masing dibandingkan dengan konstruk lainnya, tetapi indikator tersebut tetap dipertahankan dalam model karena adanya teori yang mendukung.

\section{Evaluasi Model Struktural (Uji Hipotesis)}

Langkah pertama yang dilakukan adalah melihat korelasi antara konstruk berdasarkan hasil Latent Variable Correlations. Untuk melihat signifikansi hubungan jalur antara konstruk, maka dilihat nilai t-hitung jalur seperti pada Gambar 3.

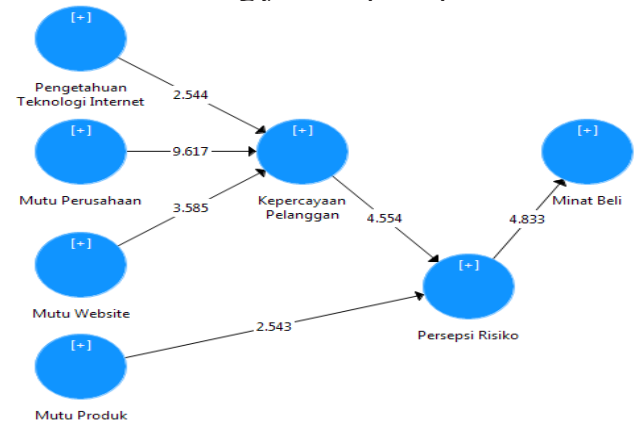

Gambar 3. Nilai t-Hitung Hubungan Jalur 
Tabel 2

Nilai Composite Reliability dan Cronbach's Alpha

\begin{tabular}{lcc}
\hline \multicolumn{1}{c}{ Konstruk } & $\begin{array}{c}\text { Composite } \\
\text { Reliability }\end{array}$ & $\begin{array}{c}\text { Cronbach's } \\
\text { Alpha }\end{array}$ \\
\hline Pengetahuan Teknologi Internet & 0,951 & 0,923 \\
Mutu Perusahaan & 0,955 & 0,929 \\
Mutu Website & 0,967 & 0,949 \\
Mutu Produk & 0,966 & 0,948 \\
Kepercayaan Pelanggan & 0,940 & 0,905 \\
Persepsi Risiko & 0,930 & 0,887 \\
Minat Beli & 0,918 & 0,869 \\
\hline
\end{tabular}

Tabel 3

Nilai Average Variance Extracted (AVE)

\begin{tabular}{|lc|}
\hline \multicolumn{1}{|c|}{ Konstruk } & AVE \\
\hline Pengetahuan Teknologi Internet & 0,867 \\
Mutu Perusahaan & 0,875 \\
Mutu Web Site & 0,908 \\
Mutu Produk & 0,905 \\
Kepercayaan Pelanggan & 0,840 \\
Persepsi Risiko & 0,815 \\
Minat Beli & 0,788 \\
\hline
\end{tabular}

Sumber: Data primer diolah

Tabel 4

Nilai Cross Loadings

\begin{tabular}{lc}
\hline \multicolumn{1}{c}{ Konstruk } & AVE \\
\hline Pengetahuan Teknologi Internet & 0,954 \\
Mutu Perusahaan & 0,944 \\
Mutu Web Site & 0,953 \\
Mutu Produk & 0,960 \\
Kepercayaan Pelanggan & 0,927 \\
Persepsi Risiko & 0,926 \\
Minat Beli & 0,896 \\
\hline
\end{tabular}

Sumber: Data primer diolah

Tabel 5

Nilai Korelasi Antara Konstruk

\begin{tabular}{|c|c|}
\hline Korelasi Antara Konstruk & $\begin{array}{c}\text { Nilai } \\
\text { Korelasi }\end{array}$ \\
\hline Pengetahuan Teknologi Internet terhadap Kepercayaan Pelanggan & 0,605 \\
\hline Mutu Perusahaan terhadap Kepercayaan Pelanggan & 0,863 \\
\hline Mutu Web Site terhadap Kepercayaan Pelanggan & 0,555 \\
\hline Mutu Produk terhadap Persepsi Risiko & $-0,538$ \\
\hline Kepercayaan Pelanggan terhadap Persepsi Risiko & $-0,625$ \\
\hline Persepsi Risiko terhadap Minat Beli & $-0,439$ \\
\hline
\end{tabular}

Sumber: Data primer diolah

Tabel 6

Nilai $R$ Square

\begin{tabular}{lc}
\hline Konstruk & R-Square $\left(\mathbf{R}^{2}\right)$ \\
\hline Kepercayaan Pelanggan & 0,792 \\
Persepsi Risiko & 0,445 \\
Minat Beli & 0,193 \\
\hline
\end{tabular}

Sumber: Data primer diolah 
Berdasarkan Gambar 3 diketahui semua hubungan jalur bersifat signifikan, karena memiliki t-hitung $>1,96$.

Adapun koefisien jalur dapat dilihat pada Gambar 4 berikut ini.

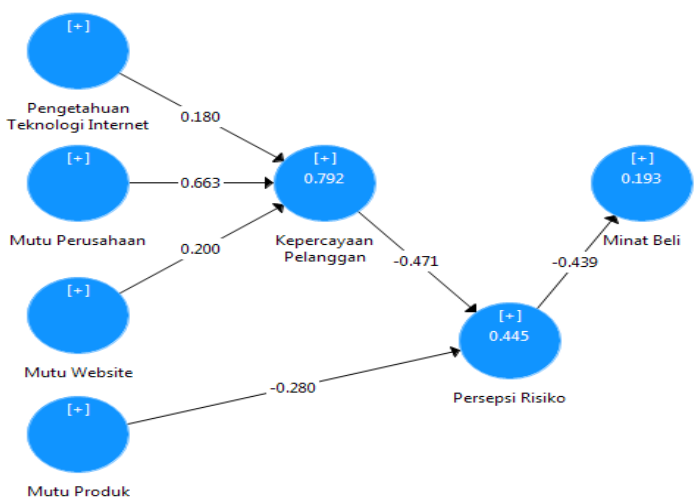

Gambar 4. Koefisien Jalur

Untuk mendapatkan persentase pengaruh antara konstruk dengan cara mengalikan nilai korelasi antar konstruk dengan koefisien jalur kemudian dikalikan seratus persen. Berikut perhitungan persentase pengaruh antar konstruk:

a. Persentase pengaruh pengetahuan teknologi internet terhadap kepercayaan pelanggan adalah:

$0,605 \times 0,180 \times 100 \%=10,89 \%$

b. Persentase pengaruh mutu perusahaan terhadap kepercayaan pelanggan adalah:

$0,863 \times 0,663 \times 100 \%=57,22 \%$

c. Persentase pengaruh mutu website terhadap kepercayaan pelanggan adalah:

$0,555 \times 0,200 \times 100 \%=11,10 \%$

d. Persentase pengaruh mutu produk terhadap persepsi risiko adalah:

$-0,538 \times-0,280 \times 100 \%=15,06 \%$

e. Persentase pengaruh kepercayaan pelanggan terhadap persepsi risiko adalah: $-0,625 \times-0,471 \times 100 \%=29,44 \%$

f. Persentase pengaruh persepsi risiko terhadap minat beli adalah:

$-0,439 \times-0,0,439 \times 100 \%=19,27 \%$

\section{Evaluasi Goodness of Fit (GoF)}

Untuk mengevaluasi GoF dalam penelitian ini, maka diperlukan nilai akhir $\mathrm{R}^{2}$ dari tabel $R$ Square.

Nilai $R^{2}$ konstruk kepercayaaan pelanggan adalah 0,792 ; artinya konstruk pengetahuan teknologi internet, mutu perusahaan dan mutu website secara simultan mampu menjelaskan variability konstruk kepercayaaan pelanggan sebesar $79,2 \%$.

Nilai $\mathrm{R}^{2}$ konstruk persepsi risiko adalah 0,445 ; artinya konstruk kepercayaaan pelanggan dan mutu produk mampu menjelaskan persepsi risiko sebesar $44,5 \%$.

Nilai $\mathrm{R}^{2}$ konstruk minat beli adalah 0,193 ; artinya konstruk persepsi risiko mampu menjelaskan minat beli sebesar 19,3\%.

Setelah dilakukan pengolahan data di atas, maka dapat melakukan validasi mode secara keseluruhan, yang dilihat dari Goodness of Fit (GoF) yang formulanya adalah sebagai berikut.

$$
\begin{gathered}
\text { GoF }=\sqrt{\overline{\operatorname{Com} \times R^{2}}} \\
\text { Com }=A V E
\end{gathered}
$$

GoF konstruk kepercayaan pelanggan adalah:

$$
G o F=\sqrt{0,840 \times 0,792}=0.816
$$

GoF konstruk persepsi risiko adalah:

$$
G o F=\sqrt{0,815 \times 0,445}=0,602
$$

GoF konstruk minat beli adalah:

$$
G o F=\sqrt{0,788 \times 0,193}=0,397
$$

Nilai GoF terbentang antara 0 sd 1 dengan interpretasi nilai-nilai: 0,1 (GoF kecil), 0,25 (GoF moderat), dan 0,36 (GoF besar). Nilai GoF yang didapat 0,816;0,602 dan 0,397 dikatakan besar karena lebih dari 0,36. Maka dapat disimpulkan, secara keseluruhan model struktur adalah fit

\section{PEMBAHASAN}

1. Evaluasi Model Pengukuran (Uji Validitas dan Reliabilitas)

Evaluasi ini meliputi dua tahap, yaitu evaluasi terhadap convergent validity dan discriminant validity.

2. Pengetahuan teknologi internet berpengaruh terhadap kepercayaan pelanggan

Nilai t-hitung hubungan jalur antara pengetahuan teknologi internet dengan kepercayaan pelanggan sebesar 2,145 > 1,96; maka hipotesis 1 diterima, pengetahuan teknologi internet berpengaruh positif terhadap kepercayaan pelang- 
gan. Nilai korelasi pengetahuan teknologi internet dengan kepercayaan pelanggan sebesar 0,605 ; berarti pengetahuan teknologi internet memberikan pengaruh positif kuat terhadap kepercayaan pelanggan. Pengetahuan teknologi internet mempengaruhi kepercayaan pelanggan sebesar 10,89\%; berarti pengetahuan teknologi internet berkontribusi positif sebesar 10,89\% terhadap kepercayaan pelanggan.

3. Mutu perusahaan berpengaruh terhadap kepercayaan pelanggan

Nilai t-hitung hubungan jalur antara mutu perusahaan dengan kepercayaan pelanggan sebesar $9,617>1,96$; maka hipotesis 2 diterima, mutu perusahaan berpengaruh positif terhadap kepercayaan pelanggan. Nilai korelasi mutu perusahaan dengan kepercayaan pelanggan sebesar 0,863; berarti mutu perusahaan memberikan pengaruh positif sangat kuat terhadap kepercayaan pelanggan. Mutu perusahaan mempengaruhi kepercayaan pelanggan sebesar $57,22 \%$; berarti mutu perusahaan berkontribusi positif sebesar 57,22\% terhadap kepercayaan pelanggan.

4. Mutu website berpengaruh terhadap kepercayaan pelanggan

Nilai t-hitung hubungan jalur antara mutu web site dengan kepercayaan pelanggan sebesar 3,585 $>$ 1,96; maka hipotesis 3 diterima, mutu web site berpengaruh positif terhadap kepercayaan pelanggan. Nilai korelasi mutu website dengan kepercayaan pelanggan sebesar 0,555 ; berarti mutu web site memberikan pengaruh positif yang sedang terhadap kepercayaan pelanggan. Mutu website mempengaruhi kepercayaan pelanggan sebesar $11,10 \%$; berarti mutu website berkontribusi positif sebesar $11,10 \%$ terhadap kepercayaan pelanggan.

5. Mutu produk berpengaruh terhadap persepsi risiko

Nilai t-hitung hubungan jalur antara mutu produk dengan persepsi risiko sebesar 2,543> 1,96; maka hipotesis 4 diterima, mutu produk berpengaruh negatif terhadap persepsi risiko. Nilai korelasi mutu produk dengan persepsi risiko sebesar $-0,538$; berarti mutu produk memberikan pengaruh negatif sedang terhadap persepsi risiko. Mutu produk mempengaruhi kepercayaan pelanggan sebesar $15,06 \%$; berarti mutu perusahaan berkontribusi negatif sebesar $15,06 \%$ terhadap ke- percayaan pelanggan.

6. Kepercayaan pelanggan berpengaruh terhadap persepsi risiko

Nilai t-hitung hubungan jalur antara kepercayaan pelanggan dengan persepsi resiko sebesar 4,554 > 1,96; maka hipotesis 5 diterima, kepercayaan pelanggan berpengaruh negatif terhadap persepsi resiko. Nilai korelasi kepercayaan pelanggan dengan persepsi resiko sebesar -0,625; berarti kepercayaan pelanggan memberikan pengaruh negatif kuat terhadap persepsi risiko. Kepercayaan pelanggan mempengaruhi persepsi risiko sebesar 29,44\%; berarti kepercayaan pelanggan berkontribusi negatif sebesar $29,44 \%$ terhadap persepsi risiko.

7. Persepsi risiko berpengaruh terhadap minat beli

Nilai t-hitung hubungan jalur antara persepsi resiko dengan minat beli sebesar 4,833>1,96; maka hipotesis 6 diterima, persepsi resiko berpengaruh negatif terhadap minat beli. Nilai korelasi persepsi resiko dengan minat beli sebesar $-0,439$; berarti persepsi resiko memberikan pengaruh negatif sedang terhadap minat beli. Persepsi resiko mempengaruhi minat beli sebesar 19,27\%; berarti persepsi resiko berkontribusi negatif sebesar 19,27\% terhadap minat beli.

\section{KESIMPULAN}

Pengetahuan teknologi internet berpengaruh positif terhadap kepercayaan pelanggan, Mutu perusahaan berpengaruh positif terhadap kepercayaan pelanggan, Mutu website berpengaruh positif terhadap kepercayaan pelanggan, Mutu produk berpengaruh negatif terhadap persepsi risiko, Kepercayaan pelanggan berpengaruh negatif terhadap persepsi resiko, Persepsi risiko berpengaruh negatif terhadap minat beli.

\section{SARAN}

Untuk meningkatkan kepercayaan pelanggan perlu diperhatikan terkait pengetahuan teknologi internet pelanggan, mutu perusahaan dan mutu website. Kepercayaan pelanggan yang tinggi dan mutu produk yang bagus akan meminimalkan persepsi risiko yang akan berujung pada minat 
beli pelanggan serta dalam pengembangan ilmu manajemen pemasaran khususnya penjualan online shopping hasil ini dapat dijadikan acuan agar kedepannya peneliti lain dapat menggunakan variabel yang sama, metode yang sama tetapi unit analisis, populasi dan sampel yang berbeda atau mencari variabel lain yang mempengaruhi minat beli pelanggan online shopping. 


\section{REFERENSI}

AG. Suyono, Sri Sukmawati, Pramono. 2012. Pertimbangan Dalam Membeli Produk Barang Maupun Jasa. Intidayu Press. Jakarta.

Caroline Bramall, Klaus Schoefer dan Sally McKechnie (2004), “The Determinants and Consequences of Consumer Trust in E-Retailing: A Conceptual Framework”, Irish Marketing Review; 2004.

Dabholkar, P.A., Sheng, X., (2015), Consumer Participation in Using Online Recommendation Agents: Effects on Satisfaction, Trust, and Purchase Intentions, The Service Industries Journal, Vol. 32, No. 9.

Erdem, T. And J. Swait (1998), Brand Equity as a Signalling Phenomenom, Journal of Consumer Psychology, Vol. 7, No. 2, pp. 131-157.

Ferdinand, Augusty. 2006. Metode Penelitian Manajemen. Semarang: Badan Penerbit UNDIP.

Hansen, Don R., dan Maryanne M. Mowen. (2005). Management Accounting, 7 th edition. SouthWestern, USA: Thomson Learning.

Indriantoro, Nur dan Bambang Supomo. 2011, "Metodologi Penelitian Bisnis Untuk Akuntansi Dan Manajemen”, Edisi Pertama. BPFE Yogyakarta

Kotler, Philip. (2003). Marketing Management, 11th Edition. Prentice Hall.Inc. New Jersey.

Kracher, Corritore C., B. and Wiedenbeck, S., (2003), On-line trust: evolving themes, a Model International Journal of Human-Computer Studies, Vol. 58, pp. pp737-58.

Mashuri. 2008. Metode Analisis Verifikatif dan Cara Menentukannya. Yogyakarta: Fakultas Psikologi UGM. 
